\title{
Práticas informacionais: nova abordagem para os estudos de usuários da informação
}

\author{
Eliane Cristina de Freitas Rocha \\ Tatiane Krempser Gandra \\ Janicy Aparecida Pereira Rocha \\ Universidade Federal de Minas Gerais - UFMG, Brasil
}

REVIEW

\begin{abstract}
Resumo
Objetivo. O estudo apresenta abordagens de pesquisa em práticas informacionais e suas implicações para o delineamento de estudos no âmbito do campo de usuários da informação.

Método. Revisão bibliográfica das bases conceituais das práticas sociais e informacionais e da produção de três grupos de pesquisa, finlandês, sueco e brasileiro, nesta abordagem.

Resultados. Todos os grupos de pesquisa apresentam as práticas informacionais como aquelas que vão além do estudo do comportamento informacional, mas que procuram escrutinar atividades relacionadas ao contato socialmente mediado com a informação (incluindo atividades comunicativas) e as práticas predominantemente relacionadas à informação em ambientes escolares, de pesquisa e do cotidiano, seja físico ou digital. Predominam, nos grupos europeus estudados, os referenciais teóricos derivados da teoria da prática de Schatzki, e no grupo brasileiro, abordagens etnometodológicas.

Conclusões. Estudos de usuários pautados pela perspectiva das práticas informacionais não devem ser baseados em modelos de comportamento informacional, nem nas perspectivas objetivista e subjetivista. Diferentes abordagens teóricometodológicas são demandadas pelo conceito de práticas informacionais e por seus diferentes entendimentos. Todavia, essa diversidade de entendimentos entre os três grupos pesquisados demonstra a potência da área: a complexidade da realidade social e o esforço constante dos pesquisadores para desvelar as diversas facetas dos fenômenos informacionais.
\end{abstract}

Palavras-chave

Comportamento informacional; Estudos de usuários; Etnometodologia; Metodologia; Práticas informacionais

\section{Information practices: new approach on information user studies}

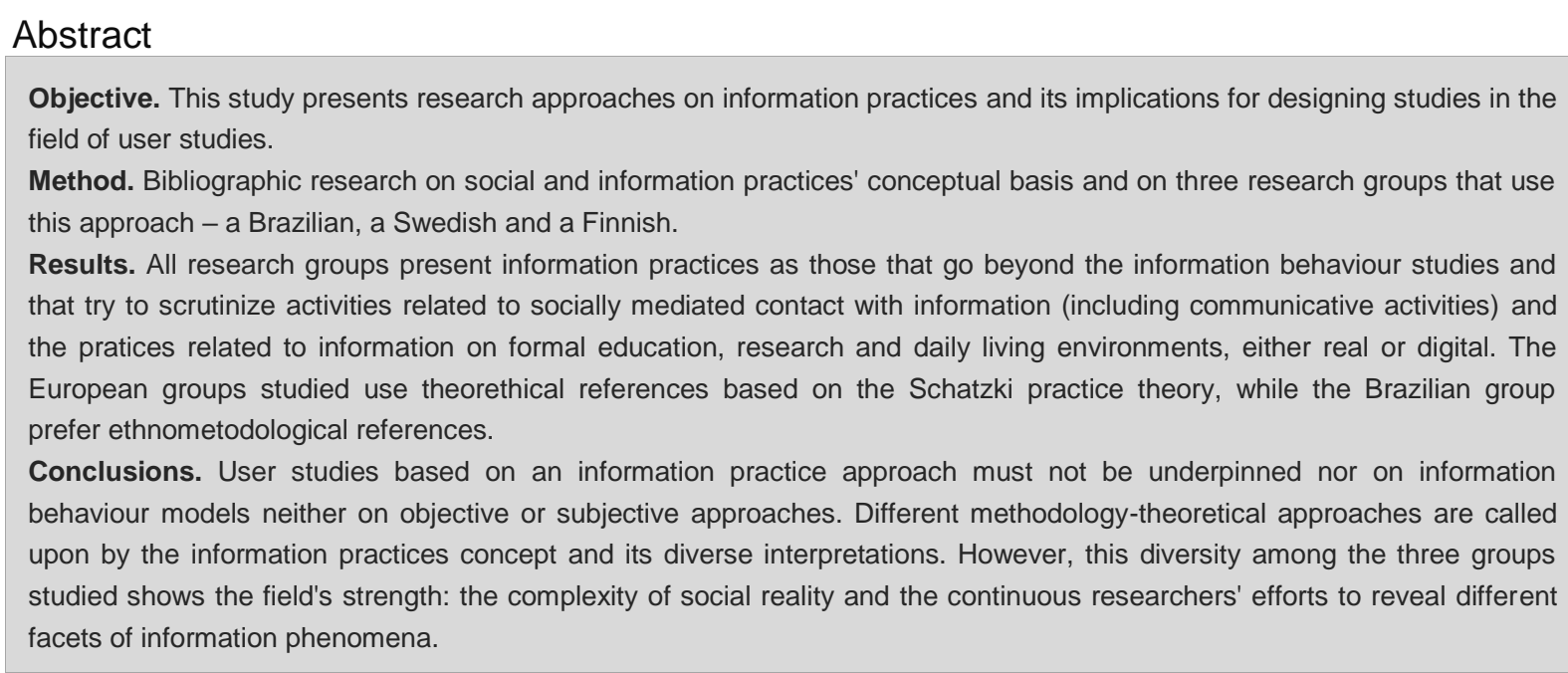




\section{Introdução}

Este trabalho procura apresentar, no âmbito da abordagem social do campo de estudos de usuários da Ciência da Informação $(\mathrm{Cl})$, o conceito de práticas informacionais, o qual tem sido abordado em trabalhos pioneiros na literatura por autores como Savolainen (2007, 2012), Talja $(1997,2005)$, Cox (2012). O propósito é esclarecer as implicações teórico-metodológicas da adoção deste conceito nos estudos de usuários, apresentando trabalhos que têm sido realizados nesta perspectiva. Para alcançar tal intento, a próxima seção deste trabalho apresenta, em linhas gerais, o conceito de práticas informacionais e sua proposição em diálogo com a $\mathrm{Cl}$ e as metodologias das ciências sociais, para, em sequência situar o leitor em estudos realizados sob essa abordagem por grupos de pesquisa de diferentes países, a saber: Finlândia, Suécia e Brasil. A metodologia adotada é a revisão bibliográfica da literatura que apresenta o conceito das práticas informacionais (SAVOLAINEN, 2007; COX, 2012; TALJA; NYCE, 2015) e a análise de conteúdo de publicações de grupos de pesquisa que adotam esse conceito (grupos de estudo da Suécia, Brasil e Finlândia que tem como foco as práticas informacionais). Por fim, são tecidas considerações sobre como proceder investigações no campo de estudos de usuários por essa perspectiva.

\section{Práticas informacionais}

A definição de práticas informacionais está presente, na $\mathrm{Cl}$, especialmente no campo de estudos de usuários da informação. Historicamente, o campo de estudos de usuários na $\mathrm{Cl}$ se volta para os usuários da informação e suas necessidades informacionais. Embora seus marcos teórico-metodológicos estejam ainda em processo de construção e amadurecimento (GONZÁLEZ-TERUEL, 2005), é possível identificar, na literatura do campo (GONZÁLEZ-TERUEL, 2005; ARAÚJO, 2016), claramente, duas abordagens recorrentes de pesquisas: a abordagem tradicional e a abordagem alternativa. A primeira, com sustentação empírica e pouco teórica, historicamente associada aos primeiros estudos de usuários, e que, em termos metodológicos, tomam o usuário como objeto de estudo de uma perspectiva objetivificante, trans-situacional, descontextualizada e desistoricizada (objetividade positivista) e normalmente lançam mão de técnicas quantitativas de coleta de dados para mensurar seu perfil e seu comportamento. A segunda, ao contrário da tradicional, propõe modelos teóricos para o comportamento informacional - como os modelos ISP de Khulthau (1991); a abordagem do sense-making de Dervin (1992) e os modelos de comportamento informacional de Wilson (1997, 1999, 2000) - e toma o usuário como um sujeito, com seus estados cognitivos, afetivos e situacionais envolvidos no contato com a informação (abordagem subjetivista), mas sem considerar profundamente o papel constitutivo do contexto em seus estudos.

A questão da importância e significado do contexto nos estudos de usuários tem sido frequentemente questionada no campo (TALJA, 1997; COURTRIGHT, 2007; SAVOLAINEN, 2012). Nas abordagens objetivistas, o usuário é tomado como um elemento acéfalo condicionado pelas estruturas sociais que não são colocadas em questão. Ora, se tais estruturas não são colocadas em questão, não há como esclarecer o que é o contexto - o contexto é apenas o pano de fundo para a pesquisa, que se volta para os usuários para medir a eficácia dos sistemas (estudos centrados no sistema). Já nas abordagens subjetivistas, o contexto não chega a ser problematizado, pois os usuários são tomados em suas individualidades e é reduzida a visão sobre o papel estruturante do contexto em seu comportamento individualizado (o estudo é centrado no usuário e perde de vista o papel estruturante do sistema).

Gandra e Sirihal Duarte (2012, 2013), Araújo (2010, 2016), Gasque e Costa (2010) e Talja (1997) acreditam que a falta de atenção ao papel constituinte do contexto social e cultural nas abordagens tradicional e alternativa de estudos é uma grande limitação. Estes autores visualizam e problematizam novas abordagens para o campo de estudos de usuários: Gasque e Costa (2010) enunciam a abordagem multifacetada e emergente, Gandra e Sirihal Duarte $(2012,2013)$ e Araújo $(2010,2016)$ a abordagem social, enquanto Talja (1997) advoga em prol da abordagem centrada na formação de conhecimento ( knowledge-formation orientation) na superação dos estudos ora centrados no sistema, ora centrados no usuário. À parte das diferenças das propostas de novas abordagens para os estudos de usuários desses autores, nota-se, na literatura do campo de estudos de usuários a emergência de estudos que procuram aprofundar a compreensão do contexto social e cultural, ensejando a formulação de outros modelos teóricos e outras abordagens metodológicas para este campo de pesquisa que se voltam para a compreensão da coletividade (GANDRA; SIRIHAL DUARTE, 2012; TALJA, 1997; ARAÚJO, 2016).

$\mathrm{Na}$ direção de novas propostas teórico-metodológicas para o campo de estudos de usuários, destaca-se a discussão acerca do conceito de práticas informacionais, emergente no final dos anos 1990 e na primeira 
década dos anos 2000, especialmente com os trabalhos de McKenzie (2003), Talja (2005) e Savolainen (2007). Para Savolainen (2007), o conceito de práticas informacionais e o de comportamento informacional são tidos como conceitos guarda-chuva para designar atividades que as pessoas realizam ao lidar com a informação. No entanto, tais conceitos estão associados a perspectivas teórico-metodológicas distintas, sendo o conceito de comportamento informacional associado ao ponto de vista cognitivo da Cl (SAVOLAINEN, 2007; GANDRA; SIRIHAL DUARTE, 2013; ARAÚJO, 2016), e o conceito de práticas informacionais, à abordagem do construcionismo social, a perspectivas neopragmáticas (da abordagem filosófica de Richard Rorty comentada por Sundin e Johannisson, 2005), e à análise de domínio da Cl de Hjørland e Albrethensen (1995), conforme Savolainen (2007).

Conforme Savolainen (2007), o conceito de práticas informacionais, muitas vezes é utilizado sem que haja uma reflexão mais profunda sobre seus significados e implicações. Para o autor, o termo foi abordado em trabalhos que escrutinavam a informação no ambiente de trabalho, como os trabalhos de Hogan e Palmer (2005) e de Taylor (1986). Nesses casos, as pessoas lidam com a informação por "ações conscientes e com propósitos bem definidos" (SAVOLAINEN, 2007, p. 123, tradução nossa) de maneira subsidiária às tarefas que realizam.

Do ponto de vista da "práxis da informação", há um pressuposto de que toda ação prática relacionada à produção, ao armazenamento, à manipulação, à busca, à transferência, à avaliação e ao uso da informação tem lugar dentro de um contexto social que ocupa o espaço de um relacionamento ainda não especificado com esta ação prática (SAVOLAINEN, 2007, p. 124, tradução nossa).

Da perspectiva neopragmatista, associada ao conceito de práticas informacionais, todo processo de busca de informação é uma prática social (SAVOLAINEN, 2007), corroborando com isso Marteleto (1995), que considera que toda prática social é uma prática informacional.

Toda prática social é uma prática informacional - expressão esta que se refere aos mecanismos mediante os quais os significados, símbolos e signos culturais são transmitidos, assimilados ou rejeitados pelas ações e representações dos sujeitos sociais em seus espaços instituídos e concretos de realização (MARTELETO, 1995, p. 92).

Embora ambas as definições tenham como alicerce a noção de que as práticas informacionais e os processos de busca de informação são essencialmente práticas sociais, bem como compreendem que as ações ocorrem em contextos específicos, Marteleto (1995) expõe de modo mais explícito que Savolainen (2007) o movimento dialético presente na sociedade e que influencia a incessante negociação de significados, discursos e representações que permeiam a relação dos sujeitos com a informação.

Tomando a prática informacional como uma prática social, é preciso estudar as práticas sociais para descortinar as práticas informacionais que lhes são subjacentes. As práticas informacionais podem ser relativas aos clássicos processos de formulação de necessidades de informação, comportamentos de busca e procura de informação e uso, mas estão além deste enquadramento proposto pelos modelos de comportamento informacional1. Talja e Nyce (2015) comentam que o próprio campo dos estudos de comportamento informacional apresenta pesquisas que superam a visão do processo lacuna-busca-uso da informação, empreendendo estudos que evidenciam porque as pessoas evitam a informação (pois ela pode ser tida como prejudicial), ou como elas tomam a informação por curiosidade ou entretenimento. Em outras palavras, nem sempre a pessoa procura por informação por estar diante de uma situação problemática ou por enfrentar uma lacuna em seu conhecimento. Conforme a teoria da prática, a busca por informação não é causada por falta de conhecimento, mas supõe grande acúmulo de conhecimento em algum domínio (TALJA; NYCE, 2005).

O foco nas práticas significa que as categorias analíticas como sense making, significados, entendimento, interpretação ou experiência não são colocadas em primeiro plano. Também a teoria da prática não se ocupa analiticamente de regras sociais, normas ou convenções. A teoria da prática se ocupa com as interconexões entre as condições materiais e recursos para as atividades, pessoas em ação e ambientes das atividades (TALJA; NYCE, 2015, p. 65, tradução nossa).

Em diversas práticas sociais, outras atividades de comunicação formal e informal entre as pessoas são evidenciadas nos estudos de práticas informacionais, tais como o contato com a informação por procuração (uma pessoa toma conhecimento de algo por ser informada por outra, sem explicitamente estar à procura de informação), prática enumerada por McKenzie (2003) no contexto problemático de mulheres à espera de gêmeos. A formação de redes de mulheres para aconselhamento e troca de informação durante a menopausa é 
apontada por Yeoman (2010). Já Harlan (2012) identificou que adolescentes criadores de conteúdos para a web atuam em comunidades de práticas dentro das quais ocorrem diversas negociações baseadas em habilidades individuais. Essas habilidades são fundamentais para que se determine as atividades de cada adolescente inserido na comunidade, cujo conhecimento é construído coletivamente.

Para apreender as práticas informacionais, é preciso estudar as práticas sociais. E seria inviável desvelar as práticas informacionais sem que o contexto social seja investigado. É por meio do estudo das práticas sociais ou culturais que são reveladas as práticas informacionais. E o estudo das práticas sociais não escapa das metodologias de pesquisa das ciências sociais e da antropologia. O debate acerca do que são práticas sociais e como elas devem ser estudadas não se inicia com o estudo das práticas informacionais na $\mathrm{Cl}$.

\section{0 que são práticas?}

Savolainen (2007) relaciona o conceito de práticas informacionais, no âmbito das ciências sociais, às abordagens dos estudos da reflexividade de Giddens (2003), dos estudos da Cognição Situada de Suchman (1987) e das comunidades de prática de Lave (1988, 1991). Por sua vez, Cox (2012) situa a abordagem da prática como uma família de teorias presentes nas ciências sociais e na filosofia, enumerando os autores Wittgenstein, Bourdieu e Giddens como expoentes, e teorias como as do Ator-Rede, Teoria da Atividade e Comunidades de Prática como exemplares dessa abordagem. Cox (2012), a esse respeito, dirá que a definição práticas informacionais é equivocada, adotando a expressão "informação em práticas sociais" (information in social practice) para se referir à apropriação da família de teorias da prática pelo campo de estudos de usuários (HIB Field). Também Talja e Nyce (2005) afirmam que há, pelo menos, duas abordagens da prática: as que problematizam a prática como atividades rotineiras que reproduzem o social e colocam o foco em sua historicidade (Bourdieu, Giddens, Wittgenstein) e as que tomam as práticas como dinâmicas, emergentes e que colocam o foco na análise dos fazeres e práticas situadas (é o caso da Teoria Ator-Rede, Cognição Situada, Ação Situada, Cognição Distribuída, Aprendizagem Situada e outras). Cox (2012) e González de Gomes (2012) situam as teorias da prática como abordagens emergentes nas ciências sociais.

Tomando as teorias da prática como um todo, o apelo dessa abordagem recai em captar o contexto que a vida social encobre, sem tomar o contexto como a estrutura totalizante, possibilitando a ação do indivíduo ser levada em conta, e também apta para a mudança e a contingência. $O$ indivíduo realiza a prática, nem autônomo, nem dopado pela cultura social. O vocabulário da prática comunica um senso de saber como social, incorporado e embutido nas rotinas e nos objetos materiais e em sua disposição, intimamente associados a propósitos, sentimentos e gostos, transitório e situado. Este é o radical desafio dos pressupostos do senso comum do saber, fundado no racionalismo e no pensamento cognitivo (COX, 2012, p. 183, tradução nossa).

As teorias da prática rompem, portanto, tanto com a perspectiva objetivista nas ciências sociais e com o pensamento subjetivista presente nas abordagens do cognitivismo ${ }^{2}$. No entanto, há diversas abordagens para as teorias da prática em si mesmas, sendo que algumas delas não problematizam o papel social das estruturas sociais como determinante para entendimento da lógica dos agentes sociais - como a etnometodologia, com raiz na fenomenologia, que explicitamente não credita categorias sociais, como as de classe social, como explicativas para os fenômenos sociais; ou a Teoria Ator-Rede de Latour (2005), que questiona a categoria do social - e outras não, como é o caso da teoria da estruturação de Giddens e o modelo praxiológico de Bourdieu. Independentemente das diferenças radicais da abordagem da prática, para Cox (2012), apoiado em Schatzki (2002), a rotina e o hábito são definidores da prática que é

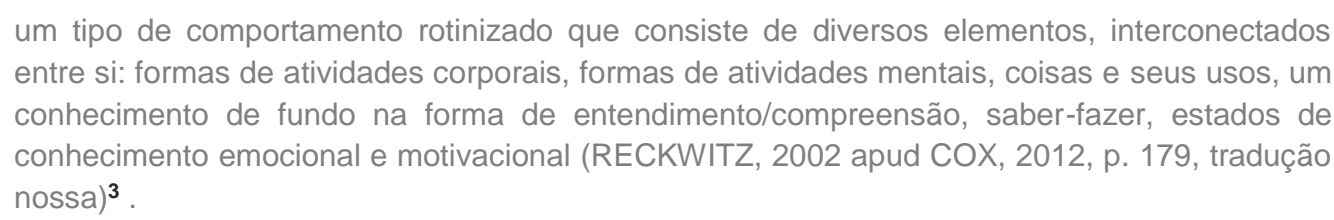

Em linhas gerais, as práticas são realizações com significado intersubjetivamente compartilhado e conformadas por acordos coletivos - acordos normalmente tácitos, compartilhados por comunidades de justificação (SUNDIN; JOHANNISSON, 2005) ou comunidades de prática. Para que exista prática, é necessário existir conhecimento compartilhado pelos membros que a realizam. O conhecimento está implícito à prática, é "situado, negociado, emergente e incorporado” (GHERARDI, 2009 citado por COX, 2012, p. 179, tradução nossa) ${ }^{4}$. 
O conceito de prática é abstrato e traz desafios para operacionalizações de pesquisa. No âmbito da $\mathrm{Cl}$, Cox (2012) exemplifica a fotografia como uma atividade familiar prática rotineira e expressiva, com informação embutida/incorporada nesta prática. Ela contém todas as características da prática: o hábito de fotografar ou de usar fotografias (como em porta-retratos, álbuns, em ambientes da casa) é um comportamento rotinizado (é possível identificá-lo em muitas ou quase todas as famílias de determinadas culturas) que normalmente envolve atividades corporais específicas (o melhor ambiente para fotografar, a maneira compartilhada de se interpretar posturas em fotos de família ou outros aspectos), que é materializado em coisas (álbuns, compartilhamento online, por exemplo) e envolve conhecimentos de fundo dificilmente explicitáveis (como ler a fotografia, como fotografar) e que são imbuídos de carga emocional e motivacional do grupo envolvido (da própria família). O que seriam as práticas informacionais neste contexto? Cox (2012) prefere não utilizar o conceito de práticas informacionais, mas sim de informação no contexto desta prática, a qual seria em parte materializada (nos próprios álbuns de família), mas dificilmente com significado estanque, pois cada rememoração da fotografia é dinâmica, e o significado partilhado para as fotos pode se alterar no tempo e no espaço. Dessa forma, a informação na prática fotográfica rotineira familiar (uma prática cultural) é compreendida como a informação como processo no contexto da $\mathrm{Cl}$, e a própria prática fotográfica tem seus significados socialmente modificados tanto pelas mudanças da materialidade fotográfica (analógicas, digitais), quanto pelas modificações contingentes da estruturação familiar ou da importância e significado social da fotografia (os quais são revelados pelos agentes e não tomados como pressuposto por categorias pré-estabelecidas pelo pesquisador).

Outro exemplo de prática, agora em contexto de ambiente de trabalho, é mencionado por Talja e Nyce (2015): o controle de tráfego aéreo. Esta prática envolve tarefas de atores, tais como pilotos e controladores de tráfego aéreo, rotinizados e contextualizados, mas em negociação constante durante a ação (característica da prática, que se situa entre a ação e o hábito).

\begin{abstract}
Por exemplo, o controle de tráfego aéreo como uma prática inclui tarefas tais como comunicação por rádio, negociação de ação e fornecimento de esclarecimento de rota. A realização desta prática é resultante de um sistema de atividade ativo que inclui linguagem compartilhada, valores e ética, formas distintas de participação - ver, ouvir, e observar - e formas de usar o corpo em interação com os materiais e recursos sociais do ambiente (TALJA; NYCE, 2015, p. 65, tradução nossa).
\end{abstract}

O exemplo de Cox (2012) relativo a atividades rotineiras cotidianas de família e o exemplo de Talja e Nyce (2015), em contexto de trabalho permitem visualizar a potencialidade do emprego da família de teorias da prática aos estudos do campo de usuários da Cl. No entanto, como abordar a prática? Quais técnicas e métodos devem ser usados? Quais abordagens teóricas da prática devem ser evocadas?

Uma abordagem profícua para a compreensão da prática é trazida pela etnometodologia, enquanto uma abordagem das ciências sociais que procura compreender o raciocínio prático e as atividades cotidianas como objeto de estudo, para desvelar como o sujeito se constrói enquanto constrói a realidade (COULON, 1995). A etnometodologia volta-se, justamente, para as atividades rotineiras e cotidianas de maneira a compreender-lhes o sentido pela perspectiva dos atores, os quais são dotados de racionalidade e reflexividade (accountability). Os sentidos e significados das práticas (das atividades da vida cotidiana) são intersubjetivamente construídos, pois a ordem social se revelaria por elementos indiciais presentes no discurso dos atores e as atividades realizadas pelos indivíduos são realizadas tendo em vista o sentido de pertença do indivíduo à coletividade (para que ele seja aceito como um membro daquele grupo).

Quanto mais institucionalizado o contexto, mais rotinizada está a ordem social, maior é o poder estruturante do contexto na determinação das ações dos indivíduos. Nos dizeres da etnometodologia, o sujeito é agido, ou é levado a agir, com suas ações tidas como naturalizadas. No entanto, da perspectiva etnometodológica, a prática é tida como atividade corriqueira da vida cotidiana que o ator social toma como rotineira (naturalizada) e que manifesta, em sua realização, a atualização de regras compartilhadas intersubjetivamente (COULON, 1995). O estudo da prática por esta perspectiva se dá pelo método documentário, o qual consiste em identificar um padrão subjacente presente no discurso (documento) dos atores sociais.

Outra abordagem da prática é colocada por Bourdieu (2003, 2008), que, diferentemente da abordagem etnometodológica, destaca o papel das estruturas sociais (como as de classe social) na determinação das práticas. Para esse autor, a prática é o produto do habitus (conjunto de disposições individuais socialmente arraigadas pelo pertencimento de classe) e dos capitais à disposição dos sujeitos nos mais diversos campos sociais. Em uma de suas obras mais célebres, Bourdieu (2008) exemplifica diversas práticas culturais, tais como a frequência a museus ou teatros como o produto de um habitus culto das classes mais elevadas por pessoas 
que tem capital cultural suficiente para decifrar o código da cultura (erudita) no campo do espaço social. A realização da prática - como a prática rotineira de ida ao teatro ou ao museu, por exemplo - é orientada por escolhas que rentabilizem ganhos simbólicos no espaço social. Embora não lance mão do conceito de comunidade de prática ou comunidade de justificação, o entendimento da prática em Bourdieu (2003) coaduna com a importância do compartilhamento do significado das ações realizadas pelos indivíduos em contexto. No caso da teoria da prática em Bourdieu, esse contexto é o do campo social (o campo científico, o campo burocrático, o campo da arte, o campo religioso, o campo da moda, entre outros), um palco de conflitos por tomadas de posição dos atores sociais (BOURDIEU, 1983).

O estudo da prática pelo modelo praxiológico de Bourdieu (2003) requer do investigador a compreensão da estrutura do campo que se analisa (quem são os atores e quais são as forças e capitais envolvidos nele) que conforma a lógica das práticas tomadas individualmente. Diante de tais percepções, Bourdieu (2003) propõe uma abordagem que pode conciliar uma relação entre o objetivismo estruturalista e a etnometodologia: o conhecimento praxiológico, que tem como objeto as relações dialéticas entre as estruturas objetivas e seu papel estruturante do conjunto de disposições estruturadas individuais que as atualizam e tendem a reproduzi-las (ou a transformá-las). O princípio básico que estrutura as práticas e as representações é o habitus. "O habitus está no princípio de encadeamento das 'ações' que são objetivamente organizadas como estratégias sem ser de modo algum o produto de uma verdadeira intenção estratégica" (BOURDIEU, 2003, p. 54). O sociólogo francês ainda faz uma ressalva em relação às tendências objetivistas:

\begin{abstract}
É preciso abandonar todas as teorias que tomam explícita ou implicitamente a prática como uma reação mecânica, diretamente determinada pelas condições antecedentes e inteiramente redutíveis ao funcionamento mecânico de esquemas preestabelecidos, "modelos", "normas" ou "papéis"... Mas a recusa das teorias mecanicistas não implica...conceder a um livre arbítrio criador o poder livre e arbitrário de, num instante, construir o sentido da situação ao projetar os fins que visam transformar esse sentido; nem, por outro lado, reduzir intenções objetivas e significações constituídas de ações e obras humanas a intenções conscientes e deliberadas de seus autores..." (BOURDIEU, 2003, p. 55).
\end{abstract}

Giddens (2003) também dá destaque, na teoria da estruturação, ao estudo da vida cotidiana, por considerá-lo essencial à análise da reprodução de práticas institucionalizadas. O conhecimento subjetivo dos atores - que se manifesta através das consciências discursiva e prática - deve ser interpretado. Os atores têm determinadas razões para exercerem uma determinada conduta, dentro de condições de cognoscitividade limitada, o que contrasta com a perspectiva etnometodológica, que pressupõe o accountability dos atores. Toda pesquisa social, para ele, teria um aspecto cultural, etnográfico ou antropológico que descortina as atividades e seus sentidos conferidos pelos atores que as realizam. Porém, "as coerções estruturais operam sempre através dos motivos e razões dos agentes, estabelecendo [...] condições e consequências que afetam opções abertas a outros, e o que eles querem das opções que têm, sejam elas quais forem" (GIDDENS, 2003, p. 366). Entender a prática, segundo a sua teoria da estruturação envolve desvelar quatro níveis: (1) elucidação hermenêutica de redes de significado; (2) investigação de contexto e forma da consciência prática; (3) identificação de limites da cognoscitividade dos agentes; (4) especificação de ordens institucionais. Para esse autor, e também para a perspectiva etnometodológica, os atores nem sempre agem de acordo com uma ordem instituída, contrariando assim o pensamento funcionalista e a abordagem positivista (GIDDENS, 2003).

A se considerar o usuário da informação pela perspectiva das diversas abordagens teórico-metodológicas das práticas (como as de Giddens, Bourdieu ou da etnometodologia), não é possível tomá-lo nem objetivamente nem subjetivamente, mas como um sujeito (e não apenas usuário de um serviço) que se constrói e constrói a realidade social e as premissas dos sistemas ou serviços que utilizam.

Alguns desafios se impõem para a abordagem das práticas informacionais, como também a todo estudo das práticas. Como delimitá-las, recortá-las de um contexto? Muito frequentemente elas são difíceis de se destacar do contexto e, portanto, uma das maneiras de abordar esse problema de escopo seria partir do entendimento dos campos sociais em que as práticas são constituídas, como na noção de campo de Bourdieu (COX, 2012). O referido autor ainda recorre a Wenger $(1998)^{5}$ para enfatizar que as práticas estão enraizadas em contextos sociohistóricos, o que lhes atribui sentido; assim os praticantes compartilham a doxa do campo em que a prática acontece, nos dizeres de Bourdieu.

Outra abordagem possível para a prática é dada pela Teoria Ator-Rede (LATOUR, 2005), que tem sido apropriada nos estudos da $\mathrm{Cl}$ e, em linhas gerais, considera os indivíduos (pessoas) como atores ou atuadores colocados em movimento pela coletividade (e não pelo social), em complexas redes de interações (incluindo 
interações homem-máquina) que precisam ser descortinadas pelo pesquisador. A prática seria vista como resultante de trabalhos negociados pela coletividade e que requer esforços contínuos de atualização, pelo trabalho de mediadores e intermediários em grupos sociais constituídos ou a se constituírem. Latour (2005) utiliza uma metáfora para ilustrar sua teoria: a do cartógrafo que sai a campo com um pedaço de papel sem utilizar contornos pré-definidos e constrói seu mapa com registros informados pelos sujeitos nos locais onde passa.

Outras perspectivas para o estudo das práticas são dadas pelas abordagens da Cognição Situada (LAVE, 1988) e da Cognição Distribuída (HUTCHINS, 1995). Ambas rompem com a tradição cognitivista (que entendia a cognição como restrita às mentes individuais) ao defenderem que os processos cognitivos se estendem ao ambiente, sendo situados ou distribuídos em contextos socioculturais específicos. Lave (1988) defende as investigações in situ, a partir da observação dos sujeitos em seus ambientes e atividades cotidianas. Hutchins (1995) entende que os processos cognitivos possuem uma natureza sociocultural e são distribuídos de forma temporal, social e por artefatos. As práticas deveriam ser estudadas, então, a partir de um olhar etnográfico, posto que estão situadas em contexto, além de serem baseadas na interação entre atores humanos e nãohumanos.

Apontadas essas possibilidades de abordagens teórico-metodológicas, busca-se identificar, na sequência, algumas manifestações dos estudos de práticas informacionais na $\mathrm{Cl}$.

\section{Estudos de práticas no campo de estudos de usuários da $\mathrm{Cl}$}

A abordagem das práticas informacionais no campo de estudos de usuários da $\mathrm{Cl}$ tem data recente (SAVOLAINEN, 2007; COX, 2012). De modo a investigar como diferentes autores têm trabalhado com tal abordagem, buscou-se autores associados à disseminação deste conceito na $\mathrm{Cl}$, sendo identificados pesquisadores que começaram a fomentar o debate sobre práticas informacionais nos estudos de usuários da informação. Esses autores são integrantes de três diferentes grupos de pesquisa sobre o tema, os quais foram selecionados para que seja apresentada breve descrição dos trabalhos desenvolvidos e de seus fundamentos teórico-metodológicos.

Ressalta-se o caráter intencional da escolha dos grupos, que ocorreu devido ao fato de os líderes desses grupos serem os precursores na introdução do conceito no campo, em diferentes países. Dos três grupos, dois são europeus e um é brasileiro: 1) grupo RIME (RIME - Research Group on Information and Media Practices ${ }^{6}$ ) da University of Tampere, na Finlândia; 2) grupo Information Practices ${ }^{7}$, da University of Borås, na Suécia; 3) grupo Práticas Informacionais ${ }^{8}$, da Universidade Federal de Minas Gerais, no Brasil.

Informações sobre os grupos de pesquisa finlandês e sueco foram obtidas em seus websites. Entretanto, buscas não identificaram o website do grupo brasileiro, sendo suas informações levantadas a partir do cadastro no Diretório dos Grupos de Pesquisa no Brasil - DGP9 e dos currículos de seus integrantes na Plataforma Lattes $^{10}$. A partir dessas informações, são apresentadas, a seguir, breves caracterizações dos mesmos.

\section{0 grupo RIME}

O grupo RIME, liderado por Reijo Savolainen, é composto por pesquisadores e estudantes de pós-graduação. Em geral, o RIME concentra-se em práticas pelas quais indivíduos, equipes e organizações processam informações durante seu ciclo de vida. As principais atividades constitutivas de tais práticas incluem produção, busca, uso, compartilhamento, gerenciamento e organização da informação em diferentes mídias.

O grupo possui 13 projetos concluídos e quatro ativos, sendo estes: 1) projeto ARONI (Argumentative online inquiry in building students' knowledge work competencies) busca desenvolver um modelo instrucional para melhoria das competências argumentativas online e a compreensão das competências estudantis em práticas informacionais do cotidiano e com as mídias; 2) projeto EIPs (Everyday information practices) procura compreender as atividades socioculturais de buscar, usar e compartilhar informação por diversas populações; 3) projeto iFuCo (Enhancing learning and teaching for future competencies of online inquiry in multiple domains), realizado em cooperação Finlândia-Chile, busca desenvolver modelos pedagógicos e práticos para pesquisas online em diversos contextos culturais; 4) grupo INFO ERGO 2 (Productivity, high quality customer experience and wellbeing at work through information ergonomics) procura desvendar a ergonomia da informação, em analogia à ergonomia do trabalho, avaliando o potencial das tecnologias da informação e comunicação para melhoria da produtividade do trabalho, entre outros aspectos. 
No website do grupo há uma lista das publicações de seus membros. Foram identificados artigos nos idiomas Inglês e Finlandês, sendo que nem todos possuem Acesso Aberto. Alguns aspectos significativos das publicações analisadas são evidenciados. Um deles é a percepção de que os trabalhos do grupo, em geral, partem da noção de busca de informação no cotidiano (everyday life information seeking), de Savolainen (1995), cujo embasamento está na perspectiva socioconstrucionista. Contudo, os artigos não apresentam referenciais teóricos consistentes, que fundamentem tal perspectiva. Isso ocorre especialmente nos trabalhos empíricos, cujos referenciais são breves e se dedicam a explanar sobre o objeto empírico adotado.

Um exemplo é o artigo de Savolainen (2011), que investiga os critérios que são usados pelos usuários no julgamento da qualidade e credibilidade da informação nas postagens de outros usuários, em fóruns de discussão na internet. $\mathrm{O}$ autor traz definições a respeito dos conceitos de qualidade da informação e credibilidade, mas não apresenta uma base teórica consistente que indique uma perspectiva orientadora. Em outro trabalho, Sairanen e Savolainen (2010) estudam as razões e estratégias que levam os sujeitos a evitar a informação, baseando-se na teoria de gestão da incerteza, oriunda da Comunicação. Os aportes teóricometodológicos se voltam para a sustentação da teoria adotada enquanto escolha apropriada para tal investigação.

O objetivo de uma das pesquisas mais recentes de Savolainen (2015) é avaliar como as emoções são expressas no compartilhamento de informações. A investigação, quali-quantitativa, apresenta referencial teórico exclusivamente sobre a dimensão emocional que influencia a interação dos sujeitos com a informação. Já Harviainen e Savolainen (2014) se dedicam a investigar práticas informacionais nos mundos sintéticos (espaços de jogos online), no intuito de compreender características da informação naquele ambiente: 1) a informação como capacidade de ação e 2) a informação como capital, implicando o potencial de usar o poder sobre os outros jogadores. Esse é um dos poucos trabalhos empíricos que utilizam o termo práticas informacionais ao longo do texto e nas palavras-chave. Além disso, é o que apresenta um referencial teórico-metodológico mais consistente e coerente com a perspectiva socioconstrucionista e, especificamente, a teoria da prática. Os autores conceituam práticas, recorrendo à Schatzki (2002), para embasar o noção de práticas informacionais, ressaltando o caráter sociocultural do conceito.

Observa-se a prevalência de estudos que adotam os seguintes objetos empíricos: mundos sintéticos, imigrantes e estudantes de diferentes níveis. Há, também, a presença acentuada das temáticas competência informacional e credibilidade da informação no ambiente digital. Ademais, percebe-se que parece haver uma mudança de foco nas investigações do grupo. Savolainen pode ser considerado o autor que introduziu efetivamente o conceito de práticas informacionais nos estudos de usuários. Porém, seus trabalhos recentes - tanto teóricos quanto empíricos - nem mesmo citam esse conceito e dão ênfase aos aspectos relativos às barreiras culturais no acesso à informação, mais precisamente à dimensão emocional presente nos processos de busca, uso e compartilhamento da informação.

\section{0 grupo Information Practices}

Situado na University of Borås (Suécia) e composto por 22 professores e estudantes de doutorado, o grupo é liderado por Annemaree Lloyd e por Ola Pilerot. Em sua apresentação, o grupo destaca o interesse em estudos qualitativos, mas não apenas, relacionados às interações de indivíduos e grupos com informações e documentos em diversos contextos, tais como escolares, de pesquisa, de trabalho e cotidiano. Outros pontos de interesse destacados são o papel das práticas informacionais nas estruturas sociais e de poder; a influência das mídias digitais nas práticas informacionais e a relação entre práticas informacionais e competência informacional.

Os projetos de pesquisa em andamento presentes na página do grupo são: 1) Competence Building for Librarians in four Swedish Regions; 2) Learning, Interaction and Mediated Communication in Contemporary Society (LinCS); 3) Reading, traditions and negotiations: Reading activities in Swedish classrooms 1967-1969. Seis projetos são listados como finalizados: 1) Bibliotek, IKT och lärande (BIKT); 2) Culture with Children; 3) EXpertise, Authority and Control on the InterneT (EXACT): a study of the formation of source credibility in Web 2.0 environments for learning; 4) FillP; 5) The Roles of School Libraries in Changing Landscapes; 6) Supporting information practices of refugees in transition and resettlement - (SpIRiT) project.

No momento da visita ao website do grupo, os três projetos em andamento estavam no idioma Inglês, assim como os projetos finalizados, dos quais apenas um estava no idioma Sueco. Entretanto, os links de acesso ao detalhamento dos projetos de pesquisa não apontaram para publicações derivadas dos mesmos. A identificação 
de publicações ocorreu a partir de visitas às páginas dos integrantes, a partir da homepage do grupo de pesquisa. Embora a maioria das publicações estivesse em Inglês, algumas estavam em Sueco e nem todas possuíam Acesso Aberto. Nessas publicações, alguns pontos se destacam.

De forma geral, os estudos adotam uma perspectiva socioconstrucionista, recorrendo à teoria da prática e às abordagens teórico-metodológicas originárias dela. Por exemplo, Pilerot e Limberg (2010) relatam adotar em seus estudos sobre práticas informacionais de estudantes uma combinação entre a abordagem discursiva baseada em Talja e McKenzie (2007) e a teoria da prática - baseada em Schatzki (2002). Os autores dedicaram atenção especial aos padrões discursivos dos estudantes acerca de suas práticas de compartilhamento da informação. Da mesma forma, Lundh, Francke e Sundin (2015) entendem as práticas informacionais, relacionadas ao julgamento da credibilidade da informação por estudantes secundaristas, como atividades situadas construídas social e discursivamente.

Hicks e Lloyd (2016) mencionam o uso da abordagem sociocultural em estudos sobre o desenvolvimento da competência informacional em refugiados, cujos panoramas informacionais sofreram ruptura com a migração. A relação entre práticas e competência informacional é frequente em trabalhos do grupo. A abordagem socioconstrucionista é pouco utilizada em estudos de competência informacional, mas esse tema, se estudado conjuntamente com práticas informacionais, pode se beneficiar de tal abordagem que permite que o foco seja direcionado às interações em contexto (HICKS; LLOYD, 2016).

O grupo produz publicações teóricas, assim como empíricas, estas em grande parte bem fundamentadas conceitualmente. Em relação ao objeto empírico, percebe-se o destaque de dois grupos: 1) refugiados (HICKS; LLOYD, 2016; LLOYD, 2016); 2) estudantes de diferentes níveis (PILEROT; LIMBERG, 2010; LUND; FRANCKE; SUNDIN, 2015), em conformidade com o público cujos títulos dos projetos de pesquisa apontam. Não obstante as pesquisas do grupo serem pautadas por um ponto em comum - teorias da prática de fundo socioconstrucionista, há variações no que concerne aos elementos destacados em cada uma - credibilidade da informação, linguagem e outros.

\section{0 grupo Práticas Informacionais}

Composto por 18 integrantes e tendo como líderes os pesquisadores Adriana Bogliolo Sirihal Duarte e Carlos Alberto Ávila Araújo, o grupo Práticas Informacionais está situado na Universidade Federal de Minas Gerais (UFMG). A partir de consultas ao currículo Lattes dos líderes do grupo, dois projetos em andamento foram identificados: 1) Práticas e regimes informacionais nas redes sociais: cultura, valores e ativismo em conflito; 2) Práticas Informacionais: abordagem social de estudos de usuários. As descrições desses projetos indicam um interesse voltado para o estudo das interações dos sujeitos entre si e com produtos e serviços informacionais em uma perspectiva que abarca dimensões históricas, sociais e culturais em diferentes contextos.

A pesquisa de Gandra e Sirihal Duarte (2012) se volta para a investigação da inclusão digital de idosos, ancorada teórico-metodologicamente na fenomenologia social de Alfred Schutz. O intuito é a descrição de como fenômenos como esses são vivenciados intencionalmente na consciência dos sujeitos a partir dessa perspectiva compreensiva, que busca apreender a natureza do mundo social pela experiência subjetiva do sujeito e utilizase dos conceitos de significado e intencionalidade para compreender os fenômenos sociais. Já o trabalho de Pinto e Araújo (2012) investiga as práticas informacionais de professores da rede municipal de ensino de Belo Horizonte, apoiando-se em uma abordagem crítica, especificamente a sociologia da prática, de Bourdieu. Ancorado em tal aporte teórico, busca-se compreender as relações de disputa entre dominadores e dominados em uma perspectiva que vai além da econômica, considerando também as marcas que essas disputas deixam na subjetividade das pessoas e que conformam a ação delas diante das situações do cotidiano, o que perpassa as dimensões simbólica e cultural.

Gandra e Araújo (2016) fundamentam sua investigação sobre a experiência de visita à um museu de ciências itinerante embasando-se no conceito de práticas informacionais enquanto um fazer etnográfico. Os autores discorrem sobre a ressignificação de vários conceitos do campo, de modo a sustentar a perspectiva adotada, buscando compreender o modo como as pessoas dão significado às suas próprias ações no que concerne à sua interação com a informação. Outro exemplo é de Araújo (2016), que explana, de maneira didática, as contribuições e os limites de cada abordagem dos estudos de usuários (tradicional, alternativa e sociocultural), se apropriando dos dados de duas pesquisas empíricas realizadas na biblioteca de uma casa de apoio para pacientes em tratamento médico. O autor destaca o olhar adotado em cada abordagem, ressaltando as dimensões ou elementos privilegiados em cada uma delas. No que se refere às práticas informacionais, numa 
perspectiva próxima à da etnografia, recorrendo à descrição densa de Geertz (Araújo, 2016), o autor evidencia aspectos da vivência cotidiana dos sujeitos, de suas interações com outros e, ainda, aspectos relacionados às interpretações e significados construídos por eles. Questão importante é a noção de identidade que, nesse caso, trata da própria significação que o sujeito dá para a sua condição, o que exerce grande influência nas formas de interação dos sujeitos com a informação.

Rocha e Sirihal Duarte (2013) e Rocha, Paula e Sirihal Duarte $(2015,2016)$ sugerem teorias cognitivas contemporâneas - Cognição Situada e Cognição Distribuída, respectivamente - como aporte teórico para pesquisas pautadas por essa perspectiva sociocultural. Apesar desse ponto em comum, as pesquisas abordam diferentes objetos empíricos - pessoas com deficiência visual e pesquisadores. Dadas as características de ambas as teorias, bem como dos objetos empíricos, os referidos autores adotam diferentes formas de abordagem metodológica.

A investigação de Rocha e Sirihal Duarte (2013) analisa a percepção da acessibilidade web por pessoas com cegueira a partir dos princípios da Cognição Situada. Considerando o pressuposto de que todo ato cognitivo é experiencial e toda ação é parcialmente improvisada ao integrar a percepção, a concepção e a ação do sujeito, mediante o ambiente em dada situação (LAVE, 1988), os autores se valeram de entrevistas e ensaio de interação no ambiente rotineiro dos participantes.

Já Rocha, Paula e Sirihal Duarte $(2015,2016)$ destacam o potencial da Cognição Distribuída para a compreensão de contextos caracterizados pelo trabalho colaborativo com vistas a um objetivo comum. A produção colaborativa de integrantes de um grupo de pesquisa é analisada a partir de um olhar etnográfico direcionado à unidade de análise, cujo limite é ampliado de mentes individuais para as relações funcionais entre todos os elementos que participam das atividades. Considera-se o grupo de pesquisa como sistema cognitivo distribuído, um local onde sujeitos interagem entre si e com um ou mais artefatos cognitivos -dispositivos de mediação que auxiliam o sujeito na execução de suas tarefas - com vistas a atingir um objetivo pré-definido (HUTCHINS, 1995).

\section{Considerações finais}

Realizar um estudo de usuários da informação tendo como perspectiva a abordagem das práticas informacionais requer, em primeiro lugar, uma renúncia às perspectivas metodológicas e teóricas objetivista e subjetivista. $\mathrm{O}$ quadro teórico de estudos sob essa perspectiva não deve partir dos modelos de comportamento informacional já conhecidos na literatura da $\mathrm{Cl}$. É preciso se atentar para os conceitos de prática e suas diferentes abordagens e implicações teórico-metodológicas.

Com base na revisão dos artigos citados nos tópicos 3.1, 3.2 e 3.3, e na descrição dos projetos de pesquisa apresentados nos websites visitados, foram identificados alguns pontos de convergência no trabalho dos três grupos, assim como alguns aspectos singulares em cada um deles. O principal ponto de aproximação é a adoção do socioconstrucionismo como base teórico-metodológica que fundamenta as pesquisas dos grupos. Dentro dessa perspectiva, os pesquisadores recorrem a diferentes abordagens para sustentar seus trabalhos, como a etnografia, fenomenologia, Cognição Situada, Cognição Distribuída, abordagem da prática, Teoria da Atividade, dentre outros. É possível observar, portanto, que todos os grupos entendem a realidade sociocultural enquanto constituinte das ações dos sujeitos.

Outro ponto em comum é a questão do alargamento das fronteiras do campo, uma vez que se percebe a adoção de objetos empíricos antes preteridos pelos estudos das abordagens tradicional e alternativa. Refugiados, imigrantes, grupos que são muitas vezes socialmente excluídos - como idosos e deficientes visuais - e quaisquer pessoas são percebidas como objeto de interesse nas pesquisas acadêmicas. Mesmo os objetos tradicionalmente estudados nas abordagens anteriores, como estudantes e cientistas, passam a ser estudados a partir de um novo olhar, o da abordagem de práticas informacionais. Os trabalhos do grupo sueco destacam, ainda, a importância de se estudar o letramento digital, tal como o grupo RIME, que também apresenta linhas de investigação nesta temática, diante dos contextos digitais.

As principais diferenças identificadas referem-se a alguns elementos que os autores apresentam, enquanto constituintes da relação dos sujeitos com a informação, em diferentes ambientes investigados. Nos trabalhos analisados dos grupos da Suécia e Finlândia, nota-se a recorrência de conceitos como os de autoridade, credibilidade e qualidade da informação. Alguns estudos da Finlândia adotam, também, a noção de informação como capacidade de ação e poder, enquanto na Suécia, a maioria das pesquisas adota o conceito de panorama informacional. Observa-se que o grupo do Brasil, de acordo com os artigos analisados, não trabalha exatamente 
com esses conceitos. Contudo, a partir da descrição dos projetos de pesquisa do mesmo, constatamos que alguns integrantes trabalham com o conceito de regime de informação, que de certo modo podem dialogar com os conceitos acima mencionados.

Em relação aos aspectos que diferem de um grupo para outro, considera-se a diversidade não como uma falha, mas como uma potência; um exemplo da complexidade da realidade social e do constante esforço dos pesquisadores que trabalham com a noção de práticas informacionais de desvelar cada vez mais facetas dos fenômenos informacionais. Por fim, propõe-se que, em trabalhos futuros, seja realizada uma revisão sistemática da literatura produzida pelos diferentes grupos de pesquisa que investigam as práticas informacionais, de modo a se realizar uma exploração mais profunda no trabalho por eles materializado.

\section{Referências}

ARAÚJO, C. A. A. Estudos de usuários conforme o paradigma social da ciência da informação: desafios teóricos e práticos de pesquisa. Informação \& Informação, Londrina, v. 15, n. 2, p. 23-39, 2010

ARAÚJO, C. A. A. Estudos de usuários da informação: comparação entre estudos de uso, de comportamento e de práticas a partir de uma pesquisa empírica. Informação em Pauta, Fortaleza, v. 1, jun. 2016. Disponível em: <http://www. periodicos.ufc.br/index.php/informacaoempauta/article/view/2970>. Acesso em: 26 Jul. 2016.

BOURDIEU, P. Algumas propriedades dos campos. In: Questões de sociologia. Rio de Janeiro: Marco Zero, 1983.

BOURDIEU, P. Esboço de uma teoria da prática. In: ORTIZ, Renato (org.). A Sociologia de Pierre Bourdieu. São Paulo: Olho D'ÁGUA, 2003. p. 39-72.

BOURDIEU, P. A distinção: a crítica social do julgamento. São Paulo: EDUSP; Porto Alegre, RS: Zouk, 2008.

COULON, A. Etnometodologia. Petrópolis: Vozes, 1995.

COURTRIGHT, C. Context in Information Behavior Research. In: Annual Review of Information Science and Technology, v. 41 , p. $273-306,2007$.

COX, A. M. An exploration of the practice approach and its place in information science. Journal of Information Science, New York, v. 38, n. 2, p. 176-188. 2012.

DERVIN, B. From the mind's eye of the user?: the sense-making qualitative-quantitative methodology. In: GLAZIER, J. D.; POWELL, R. R. Qualitative research in information management. Englewood: Libraries Unlimited,1992. p. 61-84

GANDRA, T. K.; SIRIHAL DUARTE, A. B. Usuários da informação sob a perspectiva fenomenológica: revisão de literatura e proposta de postura metodológica de pesquisa. Informação \& Sociedade: estudos (UFPB. Impresso), v. 22, p. 13-23, 2012. Disponível em: <http://www.ies.ufpb.br/ojs2/index.php/ies/article/view/10861> . Acesso em: 06 fev. 2017.

GANDRA, T. K.; SIRIHAL DUARTE, A. B. Interlocuções entre a análise de domínio e os estudos de usuários da informação: contribuições para uma abordagem sociocognitiva. In: ENCONTRO NACIONAL DE PESQUISA EM CIÊNCIA DA INFORMAÇ̃̃O, 14., 2013, Florianópolis. Anais... Disponível em: $<$ <ttp://enancib.sites.ufsc.br/index.php/enancib2013/XIVenancib/paper/view/27/15>. Acesso em: 25 jan. 2017.

GANDRA, T. K.; ARAÚJO, C. A. A. Práticas informacionais dos visitantes do Museu Itinerante Ponto UFMG. Em Questão, Porto Alegre, v. 22, n. 3, p. 201-226. 2016.

GASQUE, K. C. G. D.; COSTA, S. M. S. Evolução teórico-metodológica dos estudos de comportamento informacional de usuários. Ciência da Informação, Brasília, v. 39, n.1, p. 21-32, jan./abr., 2010.

GIDDENS, A. A constituição da sociedade. 2. ed. São Paulo: Martins Fontes, 2003.

GONZÁLEZ GOMES, M. N. G. Regime de informação: construção de um conceito. Inf. \& Soc.:Est., João Pessoa, v.22, n.3, p. 43-60, set./dez. 2012.

GONZÁLEZ-TERUEL, A. Los estudios de necesidades y usos de la información: fundamentos y perspectivas actuales. Espana: Ediciones Trea, S. L., 2005.

HARLAN, M. A. Information practices of teen content creators: the intersection of action and experiences. A Grounded Theory study. 2012. Thesis (Doctor of Philosophy) - School of Information Systems, Science and Engineering Faculty, Queensland University of Technology, Queensland, Austrália, 2012. Disponível em: <http://eprints.qut.edu.au/57125/1/Mary Harlan Thesis.pdf >. Acesso em: 16 fev. 2017. 
HARVIAINEN, J. T.; SAVOLAINEN, R. Information as capability for action and capital in synthetic worlds. Information Research, Lund, v. 19, n. 4, 2014.

HICKS, A.; LLOYD, A. It takes a community to build a framework: information literacy within intercultural settings. Journal of Information Science, New York, v. 42, n. 3, p. 334-343, 2016.

HJØRLAND, B; ALBRECHTSEN, H. Toward a New Horizon in Information Science: Domain-Analysis. Journal of The American Society for Information Science, Chapel Hall, v.46, n.6, 400-425, 1995.

HOGAN, T. P.; PALMER, C. P. Information Work and Chronic Illness: interpreting results from a nationwide survey of people living with HIV/AIDS. In: SPARKING SYNERGIES: Bringing Research and Practice Together. Proceedings... American Society for Information Science - ASIST, October 28-November 2, 2005, Charlotte, NC. Disponível em: <http://www.asis.org/Conferences/AM05/>. Acesso em: 13 jan. 2017

HUTCHINS, E. Cognition in the wild. Cambridge, MA: MIT Press, 1995.

KUHLTHAU, C. C. Inside the Search Process: information seeking from the user's perspective. Journal Of The American Society For Information Science, Chapel Hall, v.42, n.5, p.361-371, 1991.

LATOUR, B. Reassembling the social: an introduction to actor-network theory. Oxford University Press, 2005.

LAVE, J. Cognition in Practice: mind, mathematics, and culture in everyday life. Cambridge: Cambridge University Press 1988.

LAVE, J; WENGER, E. Situated Learning: legitimate peripheral participation. Cambridge: Cambridge University Press, 1991.

LUNDH, A. H.; FRANCKE, H.; SUNDIN, O. To assess and be assessed: upper secondary school students' narratives of credibility judgements. Journal of Documentation, Bingley, v. 71, n. 1, p. 80-95, 2015.

MARTELETO, R. M. Cultura informacional: construindo o objeto informação pelo emprego dos conceitos de imaginário, instituição e campo social. Ciência da Informação, Brasília, v. 24, n.1, p.89-93, 1995.

MCKENZIE, P. J. A model of information practices in accounts of everyday-life information seeking. Journal of Documentation, Bingley, v.59, n. 1, p.19-40, 2003.

PILEROT, O.; LIMBERG, L. Information sharing as a means to reach collective understanding: a study of design scholars' information practices. Journal of Documentation, Bingley, v. 67, n.2, p. 312-333, 2011.

PINTO, F. M.; ARAÚJO, C. A. A. Contribuição ao campo de usuários da informação: em busca dos paradoxos das práticas informacionais. Transinformação, Campinas, v. 24, n. 3, 2012.

ROCHA, J. A. P.; SIRIHAL DUARTE, A. B. (In)Acessibilidade na web para pessoas com deficiência visual: um estudo de usuários à luz da cognição situada. In: XIV Encontro Nacional de Pesquisa em Ciência da Informação - XIV ENANCIB, 2013, Florianópolis. Disponível em: <http://enancib.sites.ufsc.br/index.php/enancib2013/XIVenancib/paper/view/17/15>. Acesso: 19 mar. 2017.

ROCHA, J. A. P.; PAULA, C. P. A.; SIRIHAL DUARTE, A. B. Práticas informacionais de pesquisadores e criação do conhecimento científico sob a perspectiva da cognição distribuída. In: XVI Encontro Nacional de Pesquisa em Ciência da Informação, 2015, João Pessoa. XVI ENANCIB. Informação, Memória e Patrimônio: do documento às redes, 2015. v.GT4. p.1 - 21. Disponível em: <http://www.ufpb.br/evento/lti/ocs/index.php/enancib2015/enancib2015/paper/view/2749/1099>. Acesso em: 21 mar. 2017.

ROCHA, J. A. P.; PAULA, C. P. A.; SIRIHAL DUARTE, A. B. A Cognição Distribuída como referencial teórico para os estudos de usuários da informação. Informação \& Sociedade, João Pessoa, v. 26, p. 91-105, 2016.

SAIRANEN, A.; SAVOLAINEN, R. Avoiding health information in the context of uncertainty management. Information Research Lund, v. 15, n. 4, p. 15-4, 2010.

SAVOLAINEN, R. Everyday Life Information Seeking: Approaching Information Seeking in the Context of "Way of Life". Library \& Information Science Research, Boston, v. 17, p. 259-294, 1995.

SAVOLAINEN, R. Information Behavior and Information Practice: Reviewing the "Umbrella Concepts" of Information-Seeking Studies. Library Quarterly, Chicago, v. 77 n. 2, p. 109-132. 2007.

SAVOLAINEN, R. Judging the quality and credibility of information in Internet discussion forums. Journal of the American Society for Information Science and Technology, Chapel Hall, v. 62, n. 7, p. 1243-1256, 2011.

SAVOLAINEN, R. Conceptualizing information need in context. Information Research, Lund, v. 17, n.4, 2012. Disponível em: <http://InformationR.net/ir/17-4/paper534.html>. Acesso em: 08 fev. 2017.

SAVOLAINEN, R. Expressing emotions in information sharing: a study of online discussion about immigration. Information Research, Lund, v. 20, n. 1, 2015. 
SCHATZKI T. The site of the social. University Park, PA: Pennsylvania State University Press, 2002.

SUCHMAN, L. A. Plans and situated actions: the problem of human machine communication. Cambridge: University of Cambridge Press, 1987.

SUNDIN, O.; JOHANNISSON, J. The instrumentality of information needs and relevance. In: CRESTANI, F.; RUTHWEN, I. Information context: nature, impact, and role. 5th International Conference on Conceptions of Library and Information Sciences - CoLIS 2005, Glasgow, UK. Proceedings. Springer Science \& Business Media, P. 107 - 118, 2005. Springer. 2005.

TALJA, S. Constituting "information" and "user" as research objects: a theory of knowledge formations as an alternative to the information man - theory. In: VAKKARI, P.; SAVOLAINEN, R.; DERVIN, B (Ed). Information seeking in context. Taylor Graham Publishing, London, UK, 1997.

TALJA, S. The Domain Analytic Approach to Scholar's Information Practices. In: FISHER, K. E.; ERDELEZ, S.; LYNNE. Theories of information behavior. Information Today: Medford, New Jersey, 2005. p. 127-127.

TALJA, S.; MCKENZIE, P. Editors' introduction: special issue on discursive approaches to information seeking in context. Library Quarterly, Chicago, v. 77, n. 2, p. 97-108, 2007.

TALJA, S.; NYCE, J. M. The problem with problematic situations: differences between practices, tasks and situations as units of analysis. Library \& Information Science Research, Amesterdã, , v. 37, n. 1, p. 61-67, 2015.

TAYLOR, R. S. Value-Added Process in Information Systems. Norwood, NJ: Ablex, 1986.

WILSON, T. D. Information behaviour: an interdisciplinary perspective. Information Processing and Management, Amsterdam, v. 33, n. 4, p. 551-572, 1997.

WILSON, T. D. Models in information behaviour research. The Journal of documentation, Bingley, v. 55, n. 3, p. 249-270, 1999.

WILSON, T. D. Human Information Behavior. Informing Science, Santa Rosa, CA, v. 3, n. 2, p. 49-54, 2000.

YEOMAN, A. Applying McKenzie's model of information practices in everyday life information seeking in the context of the menopause transition. Information Research, Lund, v. 15, n. 4, 2010. Disponível em: <http://InformationR.net/ir/154/paper444.html>. Acesso em: 20 fev. 2016.

\section{Dados dos autores}

\section{Eliane Cristina de Freitas Rocha}

Professora da Escola de Ciência da Informação da Universidade Federal de Minas Gerais, Doutora em Ciência da Informação, Mestra em Comunicação Social, Graduada em Comunicação Social (Radialismo) e Ciência da Computação.

prof.lili.rocha@gmail.com

\section{Tatiane Krempser Gandra}

Doutoranda e mestra em Ciência da Informação, Graduada em Biblioteconomia pela Escola de Ciência da Informação da Universidade Federal de Minas Gerais.

tatikrempser@gmail.com

\section{Janicy Aparecida Pereira Rocha}

Doutoranda e mestra em Ciência da Informação pela Escola de Ciência da Informação da Universidade Federal de Minas Gerais. Bacharel em Sistemas de Informação pela Pontifícia Universidade Católica de Minas Gerais. janicy.rocha@gmail.com 


\begin{abstract}
1 Talja e Nyce (2015) mencionam que, alternativamente, ao estudo do processo lacuna-busca-uso paradigmático nos modelos de comportamento informacional, outra forma de abordar o problema do comportamento informacional seria por da análise de tarefas, como o estudo de tarefas de trabalho e de aprendizagem que demandariam subtarefas de busca ou procura por informação. A abordagem da análise de tarefas, representada por alguns estudos de Ingwersen e Vakkari não corresponde inteiramente à abordagem das práticas informacionais, pois não problematizam o contexto da realização da tarefa, tendo orientação cognitivista, com foco na solução de problemas individuais.
\end{abstract}

2 O cognitivismo é uma vertente da ciência cognitiva que procura estudar os processos mentais visando mensurá-los e controlá-los. Para esta abordagem, fatores como os afetivos e sociais não são tomados em conta para explicar as estruturas mentais. Outras abordagens da cognição humana, como a Cognição Situada e a Cognição Distribuída rompem com a visão cognitivista, entendendo as tarefas cognitivas como socialmente orientadas e construídas e constituem abordagens da teoria da prática.

${ }^{3}$ Reckwitz A. Toward a theory of social practices. European Journal of Social Theory, London, v.5, n. 2, p. 243263, 2002

4 Gherardi S. Knowing and learning in practice-based studies: an introduction. The Learning Organization, Bingley, v. 16, n.5, p.352-359, 2009.

5 Wenger E. Communities of practice: Learning, meaning and identity. Cambridge: Cambridge University Press, 1998.

6 Disponível em: <http://www.uta.fi/sis/trim/groups/rime.html>. Acesso: 13 mar. 2017.

7 Disponível em: <http://www.hb.se/en/Research/Research-Groups/Information-Practices/>. Acesso: 13 mar. 2017.

8 Disponível em: <http://dgp.cnpq.br/dgp/espelhogrupo/7020690176708850>. Acesso: 21 marc. 2017.

9 Disponível em:< http://lattes.cnpq.br/web/dgp>. Acesso: 22 marc. 2017.

10 Disponível em:<http://lattes.cnpq.br/>. Acesso: 22 marc. 2017.

\title{
$(\mathrm{cc})$ EY
}

This work is licensed under a Creative Commons Attribution 4.0

United States License.

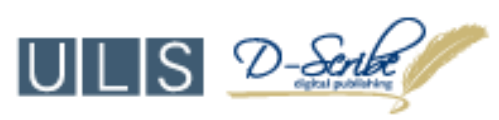

This journal is published by the University Library System of the University of Pittsburgh as part of its

D-Scribe Digital Publishing Program and is cosponsored by the University of Pittsburgh Press. 